\title{
Bone Mineral Density T-Score
}

National Cancer Institute

\section{Source}

National Cancer Institute. Bone Mineral Density T-Score. NCI Thesaurus. Code C147473.

The standard deviation of the subject's bone mineral density score in comparison to the expected normal bone mineral density of a healthy 30-year old adult. 